\title{
Colaboração na produção científica na Ciência Política e na Sociologia brasileiras
}

Recebimento:

02.2010

Aprovado:

08.2010

\author{
Glaucio Ary Dillon Soares ${ }^{1}$ \\ Cíntia Pinheiro Ribeiro de Souza ${ }^{2}$ \\ Tatiana Whately de Moura ${ }^{3}$
}

Resumo: A colaboração entre autores para a produção científica é maior nas ciências naturais e exatas do que nas ciências humanas. Mas esse cenário tem sofrido alterações e é crescente o número de artigos com mais de um autor nas ciências humanas. Não só o número de coautoria tem aumentado, mas também o interesse sobre esse fenômeno. As pesquisas sobre as redes de produção buscam identificar características de colaboração em determinadas disciplinas e/ou instituições. Neste trabalho, procuramos identificar padrões de produção científica em oito revistas de ciência política e sociologia do Brasil. O objetivo geral é demonstrar a tendência de colaboração nessas disciplinas em comparação com outras áreas. E o objetivo particular é identificar características e estilos cognitivos de produção em rede. A hipótese é que trabalhos experimentais e empíricos apresentam maior cooperação entre autores, enquanto que trabalhos teóricos tendem a ser escritos individualmente. Para isso, analisamos variáveis que indiquem se os artigos têm enfoque no tempo, no espaço e/ou em algum autor, se utilizam dados quantitativos e recursos gráficos. As características da produção em coautoria na ciência política e na sociologia podem indicar padrões de colaboração e tendência de estruturação de redes nessas disciplinas.

Palavras-chave: coautoria; redes; produção; Ciência Política; Sociologia.

\section{Introdução: Por que Coautoria?}

\footnotetext{
A s ciências sociais sempre se preocuparam com questões relativas ao avanço de suas disciplinas e o modo como o conhecimento se estrutura. Mas ainda há alguns pontos na estruturação disciplinar e profissional que merecem mais atenção.
}

Segundo Perlstadt (1998: 195), “(...) falta à sociologia um consenso sobre o que seja o ponto central de seu conhecimento e como aplicá-lo a serviço da 1. Professor e pes-
quisador - SBI/
IUPERJ.
soares.glaucio@
gmail.com
2. Mestranda em
Ciência Política-IU-
PERJ.
cprsouza@gmail.
com
3. Mestranda em Ci-
ência Política - USP.
tatiwm @gmail.com 
sociedade". Em seu artigo, o autor nota uma crise de identidade da disciplina de Sociologia nos Estados Unidos. Portanto, os sociólogos deveriam se mobilizar para divulgar melhor a sua classe tanto fora quanto dentro da academia.

Com a expansão dos cursos aplicados de graduação e de mestrado, houve o crescimento de uma classe de técnicos de sociologia aplicada que trabalham principalmente fora da academia. Eles chegam a somar $30 \%$ dos sociólogos que trabalham para o governo, a mídia, entidades sem fins lucrativos e empresas.

É apontado, também, que a estratégia de promover a visibilidade da sociologia por meio de publicações tem falhado. Isso é evidenciado pela vida curta de alguns periódicos, como o Sociological Practical Review, e a baixa empregabilidade dos seus autores.

A indefinição do perfil do sociólogo, inclusive, poderia ser um motivo para promover a maior colaboração interdisciplinar de seus autores com outras áreas. Isso porque o fenômeno crescente da coautoria estaria relacionado, também, com o aumento da interdisciplinaridade conforme a realidade se torna mais complexa (Targino, 2005; Silva et al., 2006). Resta investigar se essa suspeita se realiza ou não.

Silva et al. (2006) partem desse argumento, em seu estudo, mostrando que a interdisciplinaridade pode ser apreendida pelas redes de colaboração de autores. Em seu estudo, os autores analisam a rede de coautoria em um programa de pós-graduação em Ciência da Informação, da Universidade Federal de Minas Gerais. Com isso, procuram verificar se a produção dos professores desse programa é diferenciada, se é densa e envolve a maioria dos professores e se existe colaboração entre professores de linhas de pesquisa diferentes, evidenciando o componente da interdisciplinaridade.

A abordagem de redes sociais (social network analysis) para a análise da produção científica destaca-se no Brasil (Sobral, 2004; Silva et al., 2006; Lima et al., 2007; Maia e Caregnato, 2008), especialmente para a área de Ciência da Informação. Há uma carência de estudos dessa natureza para as outras áreas, inclusive para a Ciência Política e a Sociologia. Contudo, essa é uma abordagem já utilizada com mais intensidade fora do país para analisar a produção científica em diferentes áreas (Newman, 2004; Jackson, 2005; Fafchamps et al., 2006; Maier e Dijk, 2006; Rodriguez e Pepe, 2008).

A visualização das redes, em que os autores são pontos que se ligam entre si, conforme haja produção em coautoria, permite localizar os autores mais "produtivos", com as linhas mais densas e, também, destacá-los quanto mais diversas sejam suas ligações. Newman (2004) nota a centralidade de alguns pesquisadores que têm uma rede de colaboração mais diversa e autores com padrão 
de colaboração periférica. Alguns cientistas teriam um papel destacado de fomentar a comunicação com outros autores (betweenness centrality) e as redes seriam mais sensíveis à retirada desses indivíduos. Entretanto, Newman destaca que medir a colaboração por meio da contagem de artigos escritos em coautoria deve ser problematizado. Áreas como a matemática, por exemplo, teriam menos artigos publicados e menos autores que publicam porque a colaboração é mais restrita e o trabalho a cargo de cada autor seria maior.

Segundo seu estudo, isso está relacionado com a própria maneira pela qual a atividade de determinada área se desenvolve. A hipótese é a de que disciplinas mais teóricas, como a matemática, teriam menos colaboração do que disciplinas mais empíricas, como a biologia, por exemplo. Meadows (1974) reporta a incidência da múltipla autoria na química em $83 \%$ dos artigos, na biologia em $70 \%$ dos artigos e na física em $67 \%$ dos artigos, em contraste com a incidência da coautoria na matemática (15\%) e na história (4\%). Os dados, realmente, indicam que pesquisas laboratoriais são mais cooperativas e menos uma iniciativa individual.

Todavia, essa variação pode ser notada no interior das disciplinas. Pontille (2003) mostra como uma tradição mais próxima da pesquisa experimental promoveu a prática de coautoria na Sociologia, nos Estados Unidos. Em contraposição, a tradição mais filosófica adotada pela Sociologia francesa teria um padrão de produção científica menos colaborativo. O autor ressalta, inclusive, que o formato mais quantitativo e segmentado (Introdução; Material e Métodos; Resultados e Discussão) dos artigos publicados pelas revistas americanas favoreceria a divisão de tarefas entre os coautores.

Essa identificação da sociologia francesa e americana com a tradição e experimentação, respectivamente, perdeu sentido com a crescente diversidade interna da Sociologia e da Ciência Política no interior dos países, assim como com o crescimento gigantesco da comunicação entre sociólogos e cientistas políticos que residem em países diferentes. Mas a análise de Pontille ainda é útil para demonstrar que pesquisas mais teóricas e filosóficas tendem a ter um padrão de colaboração menor do que de pesquisas experimentais.

O aumento do número de coautorias nas últimas décadas fez surgir o interesse em estudar esse fenômeno, levando a novos conceitos como redes e núcleos. As pesquisas sobre as redes de produção buscam identificar características de colaboração em determinadas disciplinas e/ou instituições. As regularidades na estrutura de redes e suas aplicações tornam possível estudá-las, e seu impacto sobre o comportamento torna esse estudo uma necessidade (Jackson, 2005).

Assim, paralelamente ao aumento da coautoria, cresceu o número de estudos 
sobre colaboração. Alguns pesquisadores buscam identificar os processos de formação da colaboração (Fafchamps, Van der Leij e Goyal, 2006); a consolidação de pesquisas interdisciplinares (Silva, Parreiras, Matheus \& Parreiras, 2006); a extensão da especialidade disciplinar (Leahey e Reikowsky, 2008); a estrutura de programas de pós-graduação (Silva, Parreiras, Matheus e Parreiras, 2006); os padrões e estilos de colaboração (Leahey e Reikowsky, 2008); as motivações, estratégias e efeitos da pesquisa colaborativa (Merlin, 2000; Leahey e Reikowsky, 2008); a evolução do tipo de texto produzido em coautoria (Pontille, 2003); os padrões institucionalizados de produção (Pontille, 2003), as ligações entre coautores em determinados departamentos (Silva, Parreiras, Matheus \& Parreiras, 2006); a relação entre coautoria e produtividade (Glanzel, 2002), entre outros temas. $\mathrm{O}$ estudo das coautorias se diversificou.

Entretanto, pouca atenção foi dada, pelos sociólogos e cientistas políticos brasileiros, aos padrões de artigos escritos em múltipla autoria. Nos Estados Unidos, os padrões de múltipla autoria nas ciências sociais têm se tornado, crescentemente, foco de atenção e preocupação (Fischer et al., 1998; Maio e Kushner, 1981; Hudson, 1996; Wildavsky, 1986). A preocupação com a múltipla autoria tem crescido, pois houve um aumento muito grande no número de artigos produzidos em coautoria, o que indica uma mudança no padrão de colaboração e interação entre pesquisadores.

Nos Estados Unidos, o crescimento da múltipla autoria nas ciências sociais e econômicas tem sido enfatizado em diversos estudos. Hudson (1996) diz que na sociologia, em $1950,25,2 \%$ dos artigos eram produzidos em coautoria, enquanto que, em 1996, essa percentagem subiu para 53,9\%, o que corresponde a um aumento de quase $29 \%$ de coautorias no total de artigos produzidos. As colaborações na economia apresentaram uma variação semelhante, de 10,9\% sobre o total entre 1950 e 1965, para 40,0\% entre 1974 e 1993. Fischer et al. (1998) fizeram a mesma análise para a ciência política e verificaram um crescimento mais rápido da coautoria nessa disciplina. A variação verificada foi de $6,8 \%$, em 1950, para 49,2\% em 1996, ou seja, um crescimento de $42,4 \%$.

Alguns fatores têm sido apontados como determinantes para o crescimento da múltipla autoria. Nas últimas décadas, houve, nas ciências sociais, um aumento do número de profissionais, tamanho e especialidade das disciplinas. Os departamentos estão ficando maiores e mais numerosos. Com o aumento de seções e jornais especializados, surgiram mais oportunidades dos autores interagirem (Fischer et al., 1998; Hudson, 1996). Houve um aumento na oportunidade para a especialização e divisão do trabalho (Cheung e Ng, 2007; Fox e Faver, 1984; Targino, 2005).

A natureza e execução das tarefas acadêmicas têm mudado com o tempo. Pas- 
saram a haver mais esforços de coletar dados em larga escala, disponibilidade de dados e banco de dados e aumento da sofisticação técnica e estatística. Tudo isso levou à maior especialização e oportunidade de dividir o trabalho nos projetos de pesquisa (Fischer et al., 1998). A colaboração torna grandes pesquisas possíveis de serem realizadas, pois pode poupar esforço e tempo de cada membro em particular e da equipe em geral.

Além da divisão de tarefas, é importante, para alguns pesquisadores, combater o isolamento profissional, colocando-se dentro de um ou mais grupos de referência. Outra vantagem, apontada por Fox e Faver (1984), é que muitos pesquisadores se encontram mais aptos a seguir uma agenda que envolve compromisso com outros pesquisadores. Nenhum dos participantes consegue superar todos os demais nas suas respectivas áreas de competência, o que eleva a qualidade do produto, postura confirmada por Merlin (2000), que concorda que um dos benefícios atingidos pela colaboração é elevar a qualidade do artigo, mas que as razões para a coautoria, geralmente, estão relacionadas a objetivos definidos, como obter acesso a métodos, equipamentos, competências específicas e maior produtividade, particularmente nas ciências dependentes de laboratórios.

Dessa forma, é possível separar as principais razões apontadas como determinantes para o aumento da colaboração e os benefícios resultantes das pesquisas colaborativas. Os principais motivos são especialização, divisão de trabalho, aumento de pesquisas experimentais, disponibilidade de dados, crescimento da sofisticação estatística, obtenção de acesso a métodos, equipamentos, competências específicas e financiamentos. Entre os benefícios obtidos estão: tornar grandes pesquisas possíveis, poupar esforço e tempo, maior produtividade, colocar-se em um grupo de referência, troca de trabalho entre professores e estudantes e elevar a qualidade das pesquisas.

Os fatores mencionados sugerem contextos de transformações de vínculos sociais entre os pesquisadores nas ciências sociais. A estrutura desses vínculos e os padrões de relação podem ser analisados como redes. As redes "parecem ser o produto de uma conjugação entre ação orientada a fins, acaso, e herança dos padrões de vínculos anteriores" (Marques, 2007). Nesse sentido, além dos motivos a partir dos quais os indivíduos escolhem colaborar, os resultados dessa interação aparecem como mecanismos que reforçam esse fenômeno. Em outras palavras, algumas mudanças contextuais, apontadas acima, levaram os pesquisadores a optar pela pesquisa colaborativa de forma mais frequente e, uma vez escolhido esse caminho, os benefícios gerados influenciam escolhas posteriores, reforçando a colaboração.

O estudo dos padrões de colaboração é capaz de identificar a estruturação e construção de redes nas disciplinas. Porém, o objetivo dessa pesquisa é analisar 
4. O portal SciELO é um portal eletrônico que disponibiliza artigos de periódicos científicos pela Internet, como o próprio nome diz, ademais de informações como o número de citações de cada artigo e se foram produzidos com colaboração, ou em coautoria, inclusive pela nacionalidade dos autores. É uma iniciativa resultante de um projeto de pesquisa da FAPESP (Fundação de Amparo à Pesquisa do Estado de São Paulo), em parceria com a BIREME (Centro Latino-Americano e do Caribe de Informação em Ciências da Saúde) que conta com o apoio do CNPq (Conselho Nacional de Desenvolvimento Científico e Tecnológico) desde 2002. os padrões de colaboração na sociologia e ciência política brasileira e identificar seus estilos cognitivos; não é (ainda) estabelecer quais são as redes de colaboração. A principal hipótese a ser testada refere-se ao debate internacional de que pesquisas experimentais são mais propensas à colaboração.

\section{Dados e Métodos}

Analisamos os artigos publicados em oito revistas de Ciência Política e Sociologia disponibilizadas no portal SciELO (Scientific Eletronic Library Online) ${ }^{4}$ : DADOS - Revista Brasileira de Ciências Sociais, Lua Nova, Novos Estudos CEBRAP, Opinião Pública, Sociologia e Política, Sociologias, Sociedade e Estado e Tempo Social. Excluímos a Revista Brasileira de Economia e Sociologia Rural e a Revista Estudos Avançados, por serem interdisciplinares. A posteriori incluímos mais duas revistas, uma por se tratar de revista que segue os mais exigentes padrões internacionais da Ciência Política, a Brazilian Political, Science Review (apenas dois anos, 2007 e 2008) e outra por tratar das Relações Internacionais, onde as referências espaciais são quase obrigatórias, a Revista Brasileira de Relações Internacionais (a partir de 2001).

Analisamos todos os artigos publicados de 2001 até 2008, com exceção da revista Sociedade e Estado, que disponibilizava somente os números a partir de 2004 e da recente BPSR. Foram selecionados todos os artigos, que compõem o banco de dados com que trabalhamos, num total de 1979 artigos, sendo 579 de economia. Excluímos as resenhas de livros. Foram codificados os títulos dos artigos e o conteúdo dos artigos, de acordo com a presença ou ausência de alguns atributos, inclusive alguns reservados para publicações futuras. Codificamos todos os títulos dos artigos de acordo com as seguintes características: haver citação de cientistas sociais e haver referência explícita a tempo e/ou espaço, de forma definida ou indefinida. A busca de parâmetros espaciais e temporais tem origem em palestra realizada, há muitos anos, por Oswaldo Sunkel, um conhecido economista chileno, que afirmava que a Sociologia existia como se não funcionasse no tempo e no espaço. O contato do primeiro autor com historiadores e geógrafos acendeu a preocupação com esses parâmetros. Os títulos com referências a datas específicas (ex.: 1990, década de 90, século XX, etc.) foram codificados como "período definido", enquanto os que tinham menções temporais menos precisas (ex.: recente, pós-keynesiano, pós-Real) foram codificados como "tempo indefinido". Codificamos isomorficamente a variável espaço: citações de espaços geográficos definidos ou suas formas adjetivadas (Brasil, brasileiro, paulista, Américas, etc.) receberam o código "lugar definido", ao passo que referências mais abrangentes (ex.: internacional, países em desenvolvimento, nos estados) receberam o código de "espaço indefinido".

Depois dos títulos, o conteúdo dos artigos foi codificado se apresentassem: 
- "recursos quantitativos", ainda que simples (ex.: porcentagens, fórmulas, números, etc.);

- "tabelas" de dados;

- "recursos gráficos" (ex.: organogramas, gráficos, mapas, etc.);

- "regressão ou teste quantitativo" (artigos que façam uso de regressão ou outro tipo de instrumento quantitativo que envolva parâmetros estatísticos e limites de confiança).

Por fim, os artigos foram codificados, também, com referência à forma pela qual foram produzidos, com ou sem colaboração, conforme apresentassem coautoria ou não. Foram adotados os valores "não" e "sim" correspondendo a 0-1, dummies que indicavam a ausência ou presença desses atributos.

Finalmente, construímos uma escala somatória chamada "Recursos analíticos" resultante da soma dos valores das quatro variáveis "dummies", que variam ao somar de 0 a 4.

Nossa hipótese central é que a coautoria se relaciona com o estilo do artigo, com a definição básica do que é Ciência Política e Sociologia e do que não é Ciência Política e Sociologia. Especificamente, as coautorias seriam mais frequentes entre os artigos com mais ligações a concretos e menos frequentes entre os artigos abstratos que circulam no mundo das ideias puras, sem especificar os parâmetros espaciais ou temporais limitativos de sua validade.

Como a quantificação e a análise estatística imbuem limitações temporais e espaciais e essas formas de trabalhar e pensar, acarretam, também, uma forma de apresentar os resultados, esperávamos que esses atributos diferenciassem entre artigos individuais e em coautoria.

Este artigo é um dos resultados de uma pesquisa sobre redes de produção científica na Ciência Política, Sociologia e Economia. O objetivo da pesquisa, em geral, é identificar redes de coautoria nessas disciplinas e relacioná-las com estilos cognitivos de produção científica e verificar as limitações de amplitude dessas redes. Neste trabalho, em particular, o intuito é analisar os padrões de colaboração, a partir da utilização de recursos gráficos e analíticos.

\section{Análise}

As relações entre as variáveis que indicariam qual o estilo intelectual do(s) autor(es) são, todas, estatisticamente significativas e na direção prevista.

Comecemos com o estilo do artigo, se é exclusivamente discursivo ou se inclui, 
também, algum tipo de número, tão simples quanto uma percentagem. A percentagem dos artigos escritos em coautoria que usam qualquer tipo de número é de $71 \%$, bem mais do que os $46 \%$ entre os escritos individualmente. $0 x^{2}$ de mais de quase 51 mil, com um grau de liberdade, é significativo no nível de 0,000 . A associação entre as duas características é clara. O Phi é de 0.19. Esse primeiro resultado começa a confirmar a suspeita de que artigos individuais e artigos coletivos têm diferentes estilos cognitivos e intelectuais.

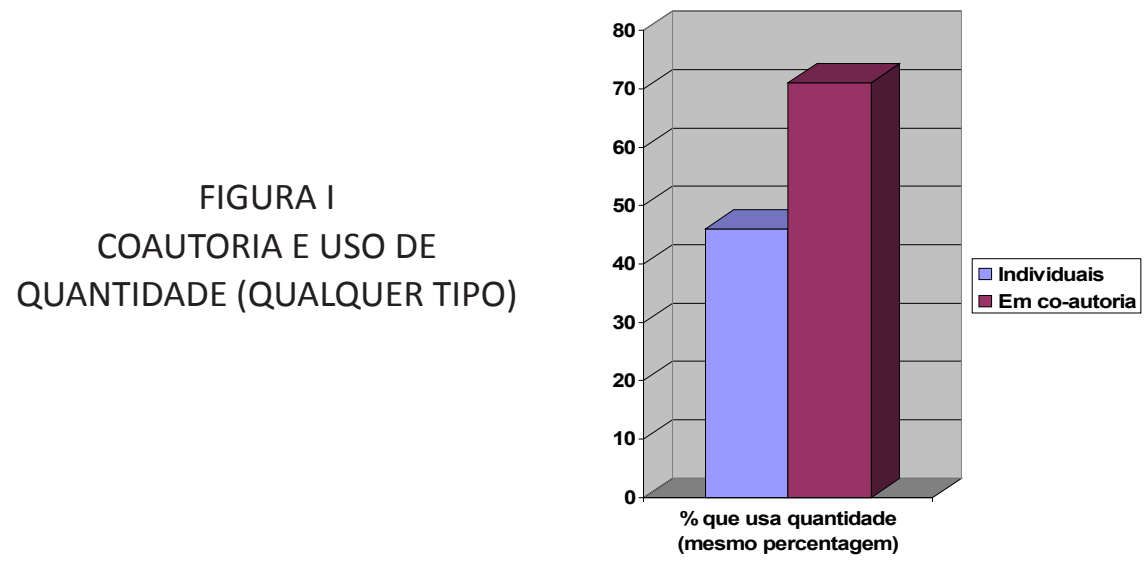

As tabelas são usadas de muitas maneiras na Ciência Política e na Sociologia e não apenas como uma forma de apresentação numérica. Em tese e pela sua lógica, não são mais do que um recurso de apresentação, mas, por tradição, as tabelas estão associadas com a apresentação numérica.

Cinquenta e quatro por cento dos artigos em coautoria usam tabelas, em contraste com apenas vinte e nove por cento dos escritos individualmente. Mais uma vez, o x² é significativo no nível de 0,000. O Phi é de 0,33.

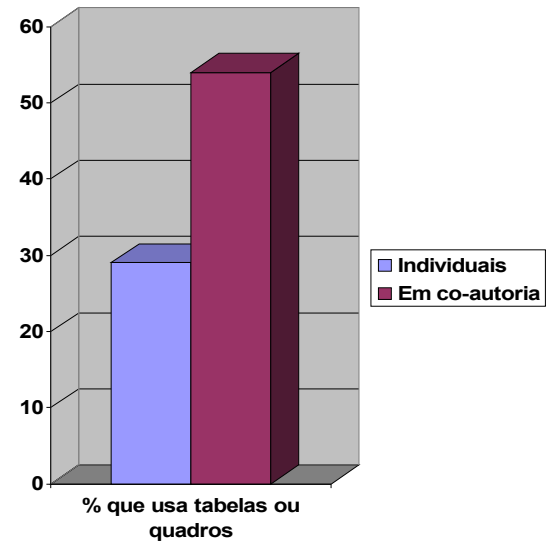

\author{
FIGURA II \\ COAUTORIA E USO DE TABELAS \\ OU QUADROS
}

Os gráficos, assim com as tabelas, podem ser usados em muitos tipos de apresentação e não apenas nas quantitativas. Não obstante, por tradição, tanto a Ciência Política, quanto a Sociologia usam gráficos como instrumentos de 
apresentação quantitativa. No que concerne aos gráficos, se confirma a associação entre o estilo do trabalho (individual vs. coautoria) e o estilo de pensar e apresentar, incluindo números e análises estatísticas e apresentações com recursos. Entre os artigos que foram escritos em coautoria, $42 \%$ utilizam gráficos ou figuras, enquanto que apenas $15 \%$ dos artigos escritos individualmente fazem uso desse tipo de recursos analítico. Nesse caso, também, o x é significativo no nível de 0,000. O Phi é 0,37.

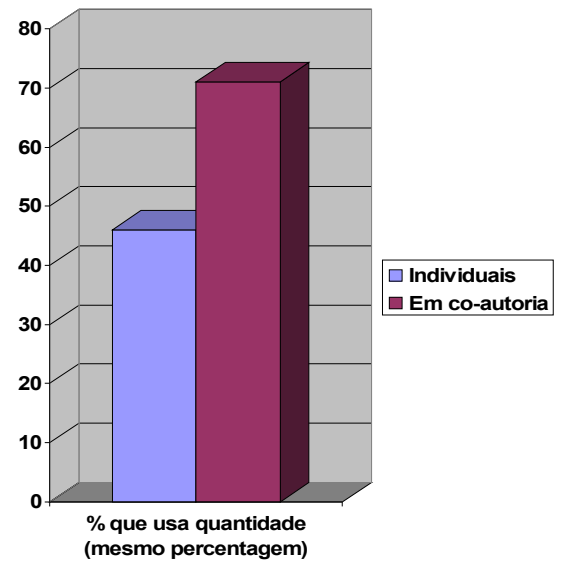

FIGURA III

COAUTORIA E USO DE GRÁFICOS

OU FIGURAS

A utilização de análise de regressão, por sua vez, pressupõe a utilização de dados quantitativos. Mas, além de ser um instrumento de análise quantitativa, esse tipo de teste estatístico está, geralmente, associado à base de dados de pesquisa empírica. Ou seja, por mais que os dados utilizados sejam secundários (coletados por outros pesquisadores), a utilização desse instrumento de análise quantitativa indica um estilo mais experimental de produção científica. Somente $7 \%$ dos artigos escritos individualmente utilizaram regressões estatísticas, em contraste com $23 \%$ dos escritos em coautoria. As diferenças são muito significativas $\left(x^{2}=60,903\right.$, com um grau de liberdade e um valor de $\left.p=0,000\right)$. O Phi é de 0,36.

\author{
FIGURA IV \\ COAUTORIA E USO DE \\ REGRESSÕES
}

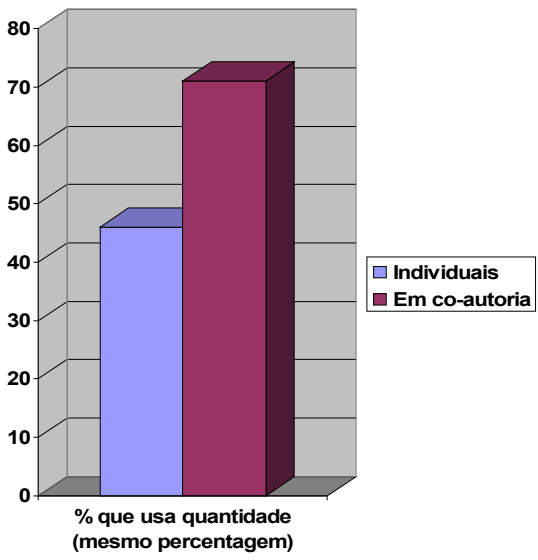


Dentre os artigos produzidos em coautoria, $71 \%$ possuem dados quantitativos; $54 \%$ possuem tabela; $42 \%$ possuem gráfico; e $23 \%$ utilizam análise de regressão. $0 x^{2}$ dessa relação é significativo no nível 0,000 e o phi é de 0,38 .

Apenas $25 \%$ dos artigos escritos em colaboração não utilizam algum tipo de recurso analítico.

Porém, a separação dos artigos nesses dois grupos, os escritos individualmente e os escritos em coautoria, não é a única maneira de prever quem usa recursos gráficos e analíticos, de quem vai além da palavra. Para demonstrar esse ponto, comparamos disciplinas. A Economia é considerada por muitos como uma disciplina cujos fazeres estão mais próximos dos das ciências exatas. $\mathrm{O}$ uso de artigos publicados pelas revistas econômicas incluídas no Scielo demonstra que essa dicotomia, Sociologia e Ciência Política, de um lado, e Economia, do outro, agrega poder explicativo ao uso de recursos analíticos e expositivos.

5. Excluindo a Brazilian Political, Science Review e a Revista Brasileira de Relações Internacionais, a primeira por ser muito recente e ter publicado poucos números e a segunda por ser de área parcialmente independente da Ciência Política.

\section{FIGURA V}

A PERCENTAGEM DE ARTIGOS EM COAUTORIA AUMENTA COM O USO DE RECURSOS ANALÍTICOS E GRÁFICOS ${ }^{5}$

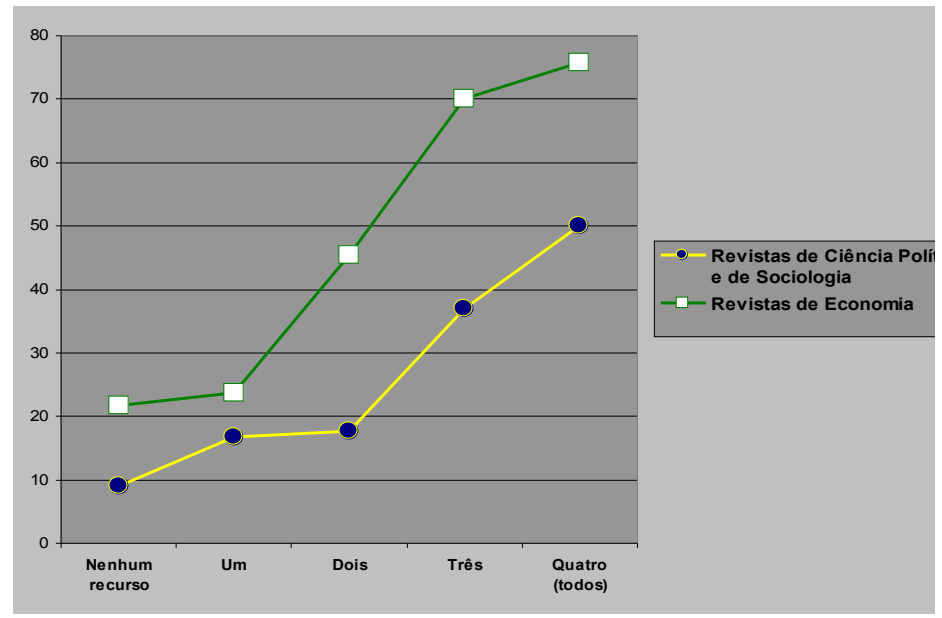

A figura acima mostra que a coautoria tem relações previsíveis tanto com a disciplina, quanto com a maneira pela qual os artigos são pensados e construídos em cada uma das disciplinas. As coautorias são mais frequentes em Economia do que nas Ciências Políticas e Sociais. As diferenças entre as disciplinas, 58\% vs. $18 \%$, são substanciais. Porém, não se devem a um efeito composicional, caso em que a relação básica seria com a maneira de pensar e construir cada disciplina. Por que não? Porque dentro de cada número de recursos analíticos e gráficos usados se observa uma diferença substancial entre as disciplinas. E vice-versa.

Por sua vez, o crescimento das coautorias com o uso de recursos analíticos e de 
apresentação dentro de cada disciplina demonstra que não se trata de uma característica disciplinar apenas. Tanto disciplina, quanto maneira de pensar e fazer o trabalho acadêmico se refletem nas coautorias.

A análise conjunta dessas variáveis requer combinar variáveis nominais (Revistas de Economia vs. Revistas de Sociologia e de Ciência Política e Coautoria vs. Individual) além de uma problemática variável de intervalo, o número de recursos analíticos e gráficos usados em cada artigo. Esse esquema classifica corretamente $78 \%$ dos casos da variável "coautorias", sendo que classifica melhor as individuais (89\%) e pior as em coautoria (53\%). O R ${ }^{2}$ de Nagelkerke 0,33 é substancial e o de Cox \& Snell 0,23. Tanto a constante, quanto as duas variáveis na equação são significativas no nível de 0,000 .

Não obstante, não devemos pensar que esses dois grupos de revistas são internamente homogêneos. Há amplas diferenças dentro de cada grupo. A adição da a Brazilian Political, Science Review e da Revista Brasileira de Relações Internacionais teve o objetivo de demonstrar que tanto a orientação da revista como a subárea da disciplina também contam na utilização de recursos diferentes. Uma revista sobre relações internacionais introduz necessariamente uma dimensão espacial por trabalhar com nações: 77\% dos artigos da Revista Brasileira de Relações Internacionais são espacialmente referidos. Já a Brazilian Political, Science Review foi criada para preencher um vácuo na divulgação de artigos empíricos com orientações "mais modernas e menos tradicionais" e, por isso, seus artigos, até agora, diferem muito dos publicados nas demais revistas, exceto Opinião Pública. Dois terços dos artigos da BPSR usam algum tipo de quantidade. Em algumas áreas, a comparação entre revistas mostra que as diferenças podem ser muito grandes: $40 \%$ dos artigos publicados na BPSR usam regressões, em claro contraste com apenas $1 \%$ dos publicados na Revista Brasileira de Relações Internacionais .

Essa análise não deixa dúvida no que concerne a ação conjunta dos dois preditores: tanto a disciplina quanto o uso de recursos gráficos e analíticos contam. A coautoria varia com a disciplina e com o "estilo" do artigo.

\section{Comentários Finais}

Buscamos mostrar com esse artigo que a colaboração na Ciência Política e na Sociologia brasileiras associa-se com a diversidade de recursos de apresentação e de análise da produção científica. Por um lado, conforme exista coautoria, há o maior emprego de referenciais numéricos, tabelas, gráficos e testes de regressão. Por outro lado, os artigos escritos individualmente tendem a seguir uma linha mais literária, mais teórica. A coautoria implica mais do que escrever junto com alguém: implica em escrever e apresentar o artigo de maneira diferente. Há 
fortes diferenças entre as revistas.

O contraste com a Economia reitera esse padrão, apresentando um número maior de artigos produzidos em colaboração. Nesse sentido, podemos dizer que a iniciativa de colaboração varia conforme a disciplina e, também, em relação à maneira de se escrever. Todavia, a tese de que a colaboração se associa com a interdisciplinaridade não pôde ser explorada nesse estudo, pois resta analisar como se organizam as redes de colaboração nessas disciplinas.

Como mencionado anteriormente, a utilização de análise de regressão estatística pode ser considerada uma indicação de trabalho empírico ou, pelo menos, um estilo experimental de produção científica. Fischer et al. (1998) fazem uma distinção semelhante entre artigos empíricos e teóricos, baseada na utilização de recursos estatísticos variados. O resultado obtido por esses autores na análise de artigos de Ciência Política nos EUA é semelhante ao encontrado nesta pesquisa. Os autores demonstram que, nos anos 1990, a múltipla autoria em artigos empíricos correspondia a 58\%, enquanto que, nos artigos teóricos, era $23 \%$. Desse modo, o resultado obtido nesta pesquisa está de acordo com o esperado, pois $45 \%$ dos artigos que utilizaram regressão como recurso analítico foram produzidos em múltipla autoria; enquanto que foi verificado apenas $15 \%$ de coautoria nos artigos que não utilizaram regressão.

Vale ressaltar que, nesta análise, constam artigos tanto de Ciência Política quanto de Sociologia. Esse fator aproxima ainda mais os resultados das duas pesquisas, pois a Sociologia apresenta uma percentagem menor de trabalhos empíricos do que a Ciência Política. Portanto, foi confirmada a hipótese de que a múltipla autoria é mais comum em pesquisas empíricas do que em pesquisas teóricas.

Abstract: The collaboration among authors for scientific production is more common in the natural and exact sciences than in the human sciences. The numbers of co-authorships has increased, both in absolute and relative numbers, as did the interest on studying this process. Researches on co-authorship networks try to identify collaboration patterns in specific subjects or institutions. The present study identifies scientific production patterns in eight Brazilian journals of Political Science and Sociology. The main goal is to compare the characteristics of articles written in collaboration with those written individually. Are they different? And the specific goal is to identify and describe the cognitive styles of network vs individual production. We tested the hypothesis that experimental and empirical papers present are more frequently written in cooperation than theoretical ones. We analyzed variables that identify time, space or author specification in the titles, and the use of quantitative data, tables, graphics and regression analysis in the text. Co-authorship characteristics in Political Science 
and Sociology may indicate collaboration patterns and point to network structures in these subjects.

Keywords: co-authorship; network; scientific production; Political Science; Sociology.

\section{Referências}

Cheung, W. \& NG, Y.-K. (2007) "Specialization and collaboration in research". Asia-Pacific Journal of Accounting \& Economics, n.14: 27-42.

Fafchamps, M.; Van Der LeiJ, M. J. \& Goyal, S. (2006) "Scientific network and coauthorship". Discussion paper series (University of Oxford), n. 256.

Fischer, B. S.; Cobane, C. T.; Vanver Vem, T. M. \& Cellu, F. T. (1998) “How many authors does it take to publish an article? Trends and patterns in Political Science". Political Science and Politics, Vol. 31, n. 4: 847-856.

Fox, M. F. \& FAVER, C. A. (1984) "Independence and cooperation in research: the motivations and costs of collaboration". The Journal of Higher Education, Vol. 55, n. 3: 347-359. GlanZEL, W. (2002) "Coauthorship patterns and trends in the Sciences (1980-1998): a bibliometric study with implications for database indexing and search strategies". Library Trends, Vol.5, n.3: 461-73.

Hudson, J. (1996) "Trends in multi-authored papers in economics". Journal of Economics Perspectives, Vol. 10, n. 3: 153-158.

JACKSON, M. O. (2005) The economics of social networks. Versão impressa da apresentação no 9 ㅇ World Congress of the Econometric Society.

LeAHEY, E. \& ReIKowsky, R. C. (2008) "Research specialization and collaboration patterns in sociology". Social Studies of Science, n. 38/3: 425-440.

Lima, R. A.; Velho, L. M. L. S. \& Faria, L. I. L. de (2007), “Indicadores bibliométricos de cooperação científica internacional em bioprospecção". Perspectivas em Ciência da Informação, Vol. 12, n. 1: 50-64.

Maia, M. de F. S.; Caregnato, S. E. (2008), "Co-autoria como indicador de redes de colaboração científica". Perspectivas em Ciência da Informação, Vol. 13, n. 2: 18-31.

Maier, G. \& DiJK, J. VAN (2006), "Co-authorship in Regional Science: A Network Approach". Institute of Regional Development and Environment. Vienna University of Economics and Business Administration. SRE Discussion, (2006/08): 1-30.

Maio, G. de \& Kushner, H. W. (1981), “Quantification and Multiple Authorship in Political Science". The Journal of Politics, Vol. 43, n. 1: 181-193.

Meadows, A. J. (1974), Communication in Science. London: Butterworths. 
MARques, E. (2007), "Mecanismos relacionais". Revista Brasileira de Ciências Sociais, Vol. 22, n. 64.

MerLIN, G. (2000), "Pragmatism and self-organization research collaboration on the individual level". Research Policy, 29, p. 31-40.

Newman, M. E. J. (2004), "Coauthorship networks and patterns of scientific collaboration". PNAS, April 6, Vol. 101, Suppl. 1: 5200-5205. Disponível em: <http://www.pnas.org/cgi/doi/10.1073/pnas.0307545100> Acesso em: Março de 2009.

Perlstadt, H. (1998), "Accreditation of Sociology Programs: A Bridge to a Broader Audience". Canadian Journal of Sociology, 23 (1/1): 195-207.

Pontille, D. (2003), "Authorship Practices and Institutional Contexts in Sociology: Elements for a Comparison of the United States and France". Science, Technology \& Human Values, Vol. 28, n. 2: 217-243.

Rodriguez, M. A. \& Pepe, A. (2008), “On the relationship between the structural and socioacademic communities of a coauthorship network": 1-11

Sobral, F. (2004), "Desafios das Ciências Sociais no desenvolvimento científico e tecnológico contemporâneo". Sociologias, Porto Alegre, ano 6, n. 11, jan/jun: 220-237.

Silva, A. B. e O.; Matheus, R. F.; Parreiras, F. S. \& Parreiras, T. A. S. (2006), "Análise de redes sociais como metodologia de apoio para a discussão da interdisciplinaridade na ciência da informação". Ci. Inf., Brasília, Vol. 35, n. 1: 72-93.

Stokes, T. D. \& HaRtLey, J. A. (1989), "Coauthorship, Social Structure and Influence within Specialties". Social Studies of Science, Vol. 19, n. 1: 101-125.

TARGINO, M. DAS G. (2005), "Artigos científicos: a saga da autoria e co-autoria". Intercom - Sociedade Brasileira de Estudos Interdisciplinares da Comunicação. XXVIII Congresso Brasileiro de Ciências da Comunicação - Uerj - 5 a 9 de setembro: 1-14.

Vilan Filho, J. L.; Souza, H. B. de \& Mueller, S. (2008), "Artigos de periódicos científicos das áreas de informação no Brasil: evolução da produção e da autoria múltipla". Perspectivas em Ciência da Informação, Vol. 13, n. 2: 2-17.

Wildavsky, A. (1986), "On collaboration". American Political Science Association, Vol. 19, n. 2: 237-248. 